\title{
Effect of Surface Functionalized Alumina Nanoparticle on the Mechanical and Wear Behavior of Reinforced Acrylonitrile Butadiene Styrene Polymer Composite
}

\author{
Praful A. Kakde \\ Visvesvaraya National Institute of Technology, Nagpur- 440010 (India)
}

\begin{abstract}
Alumina nanoparticles were successfully functionalized with a bi-functional coupling agent, (3-methacryloxypropyl) trimethoxysilane (MPS), through a neutral solvent method. MPS was found to be covalently bound with the nanoparticles. The linked MPS was melt mixed with Acrylonitrile butadiene styrene (ABS) polymer through a twin screw extruder. Tensile test results revealed the Young's modulus and strength increasing with particle loading. Microscopic examinations revealed the presence of large plastic deformations at the micron scale in the nanocomposites in agreement with the observed strengthening effect of functionalized nanoparticles. Pin on disk wear test revealed decreased in wear rate as compared to virgin polymer up to 30\%.Thermo-gravimetric analysis (TGA) did not show any significant change in the thermal degradation of the nanocomposite as compared with the neat polymer.
\end{abstract}

Keywords: ABS, Alumina, Crystallinity, Mechanical properties, Polymer nano-composite, Wear

\section{Introduction}

Particulate polymer nanocomposites have received significant attention during the past decade. They are a new class of multiphase materials containing dispersion of particles, typically in the range of $1-100 \mathrm{~nm}$. They represent an attractive set of inorganic-organic materials provide a convenient macroscopic system to study basic scientific issues concerning confined and tethered polymers at a new scale intermediate between nano- and microscale. The incorporation of low volume additions (1-5 wt.-\%) of highly anisotropic nanoparticles, such as layered silicates or carbon nanotubes, have resulted in property enhancements with respect to the neat polymer that are comparable with that achieved by conventional loadings (15-40 wt.-\%) of traditional fillers. A number of experimental investigations on these materials have indicated that polymer nanocomposites exhibit new and improved properties that are not displayed by the individual phases or by their conventional composite counterparts [1-7]. In polymer-clay nanocomposites, the clay particles are about the same size as the polymer molecules themselves, which enables them to be intimately mixed and chemically bonded to each other.[8] The improvement in mechanical properties such as tensile strength, tensile modulus [9-13],decreased thermal expansion coefficient, increased solvent resistance, outstanding diffusion barrier properties $[6,7,14]$ and flame retardant capability $[15,16]$ are a few selected examples of the advantages provided by this new class of materials. The presence of nanoparticles generally improves the elastic modulus and does not worsen the rheological and processing behavior and the optical properties of the polymer matrix. As compared with other nanomaterial's such as carbon nanotubes, alumina is cheaper and has the ability to be functionalized for nanocomposite fabrication [17]. ABS polymer was chosen due to excellent strength, rigidity, toughness and possessing good chemical, stress-cracking resistance to inorganic salt solutions, alkalis, mineral acids.
Upon incorporation of the alumina nanoparticles into the ABS polymer matrix, the obtained nanocomposite has potential applications in automobile, piping, electronic packaging and sport industries. The existing challenge in composite fabrication is to improve the wear resistance with the incorporation of nanoparticles with high hardness. This can be achieved by improving the response of the material to an applied stress which strongly depends upon the linkage between the filler and the polymer matrix. The interfacial interaction between the inorganic nanoparticle and the organic polymer matrix plays a crucial role in determining the quality and properties of the inorganic-organic nanocomposite [18-20]. Surface functionalization of the nanoparticle with a surfactant is subsequently important not only to stabilize the nanoparticlebut also to render the nanoparticle compatible with the polymer. [21]

Alumina nanoparticles $[17,22-25]$ and (3methacryloxypropyl) trimethoxysilane (MPS) [17, 2628]have been used as filler and surfactant, respectively, for nanocomposite fabrication. The functionalization of the alumina nanoparticles is normally carried out in a $\mathrm{pH}=4$ acidic alcoholic solution [22]. However, from the Pourbaix diagram [29], alumina will get dissolved and form aluminium ions in solutions with $\mathrm{pH}$ values lower than 4.25 or higher than 10.25. After treatment with a normal acidic solution, the more reactive alumina nanoparticles will dissolve and reshape into agglomerated bulk form existing in the possible salt form rather than alumina any more. The other reported method used a high temperature reaction at the silane toluene refluxing point to functionalize the nanoparticles with MPS [30].

In this paper, the alumina nanoparticles were functionalized by using neutral MPS tetrahydrofuran (THF) solution at room temperature. FT-IR analytical results indicated that MPS was covalently bound onto the nanoparticle surface. The functionalized alumina nanoparticle filled vinyl ester 


\section{International Journal of Science and Research (IJSR) \\ ISSN (Online): 2319-7064}

Index Copernicus Value (2013): 6.14 | Impact Factor (2014): 5.611

nanocomposite showed enhanced mechanical properties under microtensile study. The fracture surface study showed an interfacial effect with the addition of the functionalized nanoparticles. The addition of the nanoparticles was observed to have no deleterious effect on the thermal stability as compared to the neat resin.

\section{Experimental}

\section{Materials}

The polymeric matrix used was ABS, MIF 45(manufactured by the BEPL ChemicalCompany). The polymer has a density of $1.045 \mathrm{gcm}^{-3}$ anda viscosity of 350 centipoise (cP) at room temperature.Alumina (aluminium oxide, $\mathrm{Al}_{2} \mathrm{O}_{3}$, Nanophase Technologies)nanoparticles with an average diameter of $40 \mathrm{~nm}$ and a specificsurface area of $44 \mathrm{~m}^{2} \mathrm{~g}^{-1}$ were functionalized and used as ananofiller for the nanocomposite fabrication.3-(Trimethoxysily)propyl methacrylate (MPS), tetrahydrofuran(THF, anhydrous) purchased from Sigma-Aldrich Chemical Company. All thechemicals were used as received without further treatment.

\section{Surface functionalization of alumina nanoparticles}

In order to disperse alumina nanoparticles uniformly in thePolymer matrix, MPS was used to functionalize the nanoparticles due toits bi-functional nature: hydrolysable group $\left(-\mathrm{Si}\left(\mathrm{OCH}_{3}\right)_{3}\right)$ andunsaturated carbon-carbon double bond. The first functionalgroup can be hydrolyzed and chemically bound to thenanoparticle surface while the latter functional group can becopolymerized with the resin monomer and form a nanocomposite. The nanoparticle functionalization is described briefly here. Alumina nanoparticles wereadded into a mixture of $4 \mathrm{~g}$ MPS and 50 $\mathrm{ml}$ THF. The resultingcolloidal suspension was stirred for one hour and precipitated by sedimentation at roomtemperature. The precipitated nanoparticles were rinsed withTHF to remove the excessive MPS and dried completely in anoven at room temperature to remove the solvent.

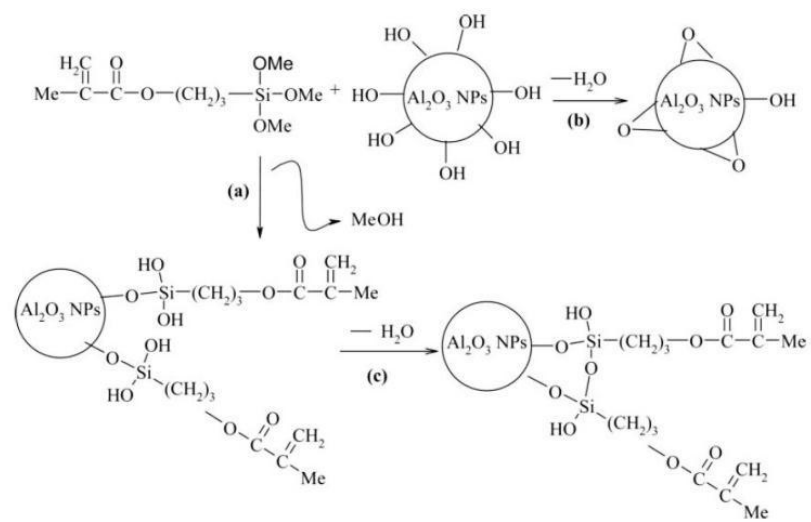

Figure 1: Scheme of (a) alumina nanoparticle functionalization with MPS, (b) dehydration of hydrolyzed alumina nanoparticles, (c) condensation of hydrolyzed MPS [17].

\section{Nanocomposite fabrication}

MPS functionalized alumina nanoparticles (specific weightpercentage) were dispersed into ABS polymer by melt mixing technique using twin screw extruder(M/s APV Baker,UK, and Model: MP19PC).In this process, the temperature profiles in the barrel were $200^{\circ} \mathrm{C}, 220^{\circ} \mathrm{C}, 230^{\circ} \mathrm{C}$, $240{ }^{0} \mathrm{C}, 250{ }^{0} \mathrm{C}$ from hopper to die. The screw L/D was 25 andscrew rotation rate of $60 \mathrm{rpm}$ was used. Tensile, Flexural and Izod impact samples(according to ASTM D-638 M91, ASTM D 790 and ASTM D 256-92 respectively) wereprepared using an injection molding machine $(\mathrm{M} / \mathrm{s}$ Boolani Engineering, Mumbai) with a barrel temperature of $220{ }^{\circ} \mathrm{C}, 250{ }^{\circ} \mathrm{C}, 280^{\circ} \mathrm{C}$.

\section{Characterization}

A Fourier transform infrared (FT-IR) spectrometer was used to test the physicochemical interaction between MPS and alumina nanoparticles and the change of the MPS functional group after the nanoparticle treatment. FT-IR spectra were recorded in an FT-IR spectrometer (Jasco, FT-IR 420) in transmission mode under dried nitrogen flow (10 cubic centimeters per minute, ccpm) conditions. The as-received and MPS-treated alumina nanoparticles filled nanocomposites were characterized by thermo-gravimetric analysis (TGA, PerkinElmer) from $25^{\circ} \mathrm{C}$ to $600^{\circ} \mathrm{C}$ with an argon flow rate of $50 \mathrm{ccpm}$ and a heating rate of $10^{\circ} \mathrm{C} / \mathrm{min}$. Thermal degradation of the nanocomposites with different nanoparticle loadings was studied by TGA. The mechanical properties of the fabricated nanocomposites were evaluated by tensile tests following the American Society for Testing and Materials (ASTM, 2005, standard D 637). An Instron 5544 testing machine was used to measure the tensile strength and Young's modulus. The dogbone shaped specimens were prepared as described in the Nanocomposite fabrication section. The specimen surfaces were smoothed with an abrasive sand paper (1000) and the sanding strokes were made in the direction parallel to the long axis of the test specimen. The specimens were conditioned for more than 4 hours in an ambient environment before measurement, as required by the ASTM. Five to seven specimens per sample were tested. Specimens that broke at some obvious fortuitous flaws or near a grip were discarded. A crosshead speed of $0.1 \mathrm{~mm} \mathrm{~min}^{-1}$ was used and strain ( $\mathrm{mm}$ $\mathrm{mm}^{-1}$ ) was calculated by dividing the crosshead displacement $(\mathrm{mm})$ by the gage length $(\mathrm{mm})$. A scanning electron microscope (SEM, JEOL field emission scanning electron microscope, JSM-6700F) were utilized to examine the fracture surfaces. The SEM specimens were prepared by sputter coating a thin gold layer approximately $3 \mathrm{~nm}$ thick on a polished nanocomposite sample. Wear analysis were done using pin on disk tribometer.

\section{Result and Discussion}

\section{FT-IR Analysis of nanoparticles}

A FT-IR spectrum of the pure MPS and MPS-functionalized alumina nanoparticles is shown in Fig. 2. The characteristic absorption peaks at $818 \mathrm{~cm}^{-1}, 1089 \mathrm{~cm}^{-1}$, and $1638 \mathrm{~cm}^{-1}$ are due to $-\mathrm{Si}-\mathrm{OCH} 3, \mathrm{Si}-\mathrm{O}$ and $\mathrm{CLC}$ vibrations of MPS, respectively. The peaks at $1721 \mathrm{~cm}^{-1}$ and $1167 \mathrm{~cm}^{-1}$ are due to the $\mathrm{CLO}$ and $\mathrm{C}-\mathrm{O}$ vibrations, respectively. The disappearance of the peak at $818 \mathrm{~cm}^{-1}$ characteristic of - SiOCH3 and the existence of other peaks characteristic of MPS in the MPS treated nanoparticles indicate the complete reaction between MPS and hydrolyzed alumina nanoparticles as shown in Fig. 1.

\section{Volume 5 Issue 2, February 2016}




\section{International Journal of Science and Research (IJSR) \\ ISSN (Online): 2319-7064}

Index Copernicus Value (2013): 6.14 | Impact Factor (2014): 5.611

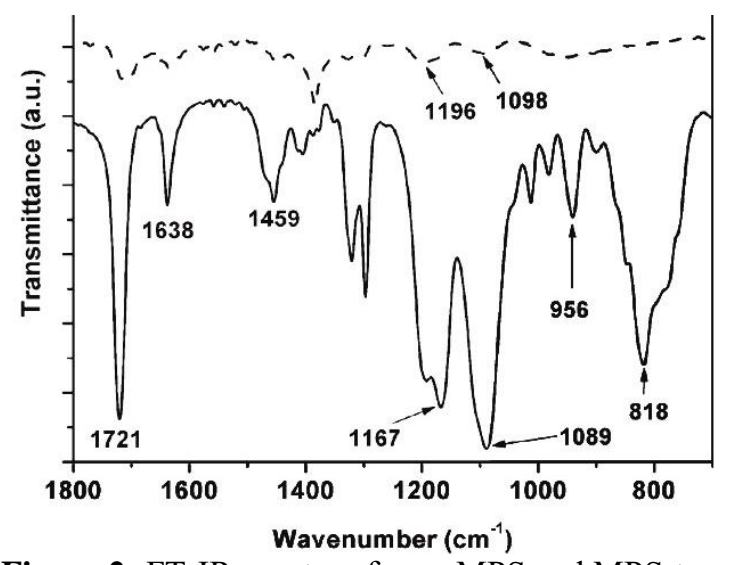

Figure 2: FT-IR spectra of pure MPS and MPS-treated alumina nanoparticles

\section{Dispersion of nanoparticles}

Dispersion of nanoparticle in to the polymer matrix can be investigated from Fig. 3 and Fig. 4. The TEM analysis reveals that surface functionalized alumina nanoparticles are dispersed properly in to the ABS polymer matrix whereas the as received alumina nanoparticles form agglomerations even at low particles loadings. This explains the increased compatibility of inorganic nanoparticles with the organic ABS polymer matrix due to the MPS surface functionalization nanoparticles.

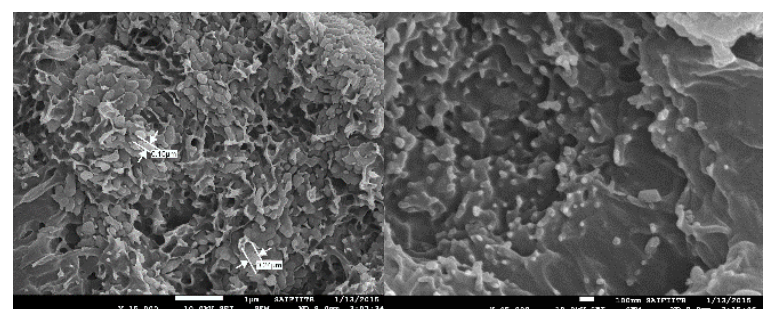

Figure 3: TEM images for MPS-treated alumina nanoparticles dispersion in ABS.

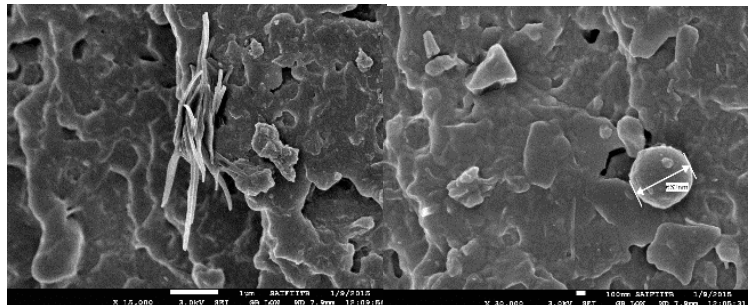

Figure 4: TEM images foruntreated alumina nanoparticles dispersion in ABS.

\section{X-Ray Diffraction}

Crystalinity

The XRD data of a composite containing variable amounts $(0,3,5$ wt.\%) of both functionalized and as received alumina filler percentage is shown in Fig. 5 and Fig. 6.Two major crystalline peaks are at ca. $2 \theta=20^{\circ}$, which, are characteristic of the amorphous form of ABS. It was observed that the ABS component was amorphous while the alumina phase was, with no discernable peaks, amorphous. Crystalinity data obtained from X'pert software by using striping $\mathrm{k}$ alpha 2 methods has shown in fig. 9. With addition of untreated alumina nanoparticles, percentage crystalinity of nanocomposite initially increases to high value but then shows regular decrease with further addition. This may be due to the agglomeration of nanoparticles with increased addition of reinforcement. On the contrary, with the addition of surface treated alumina nanoparticles, the percentage crystalinity of nanocomposite shows regular increase shows good dispersion and no agglomeration even with high particles loadings.

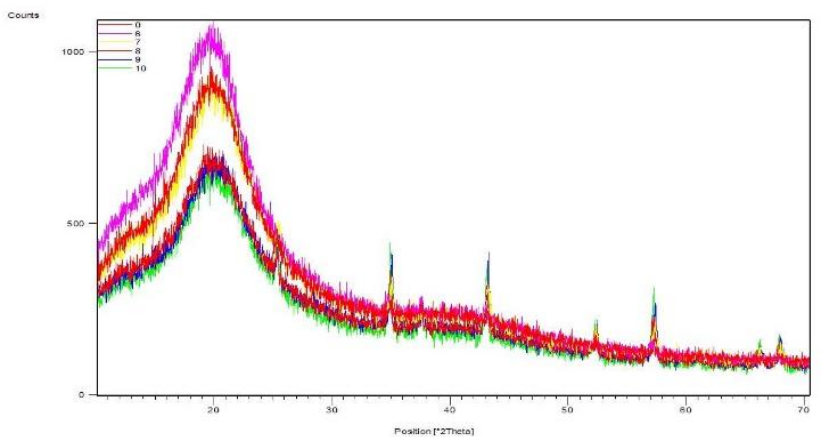

Figure 5: XRD spectra of surface functionalized alumina nanoparticles filled polymer composite.

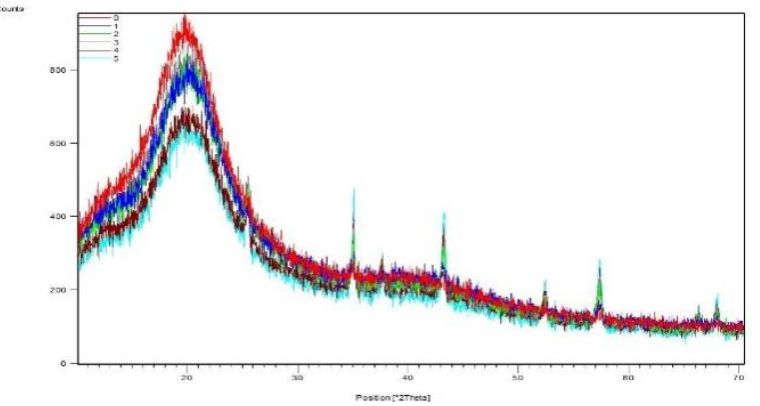

Figure 6: XRD spectra of as received alumina nanoparticles filled polymer composite

\section{TGA}

Thermo gravimetric analysis (TGA) of nanocomposites with $(0,1,2,3,4,5$ wt. \%) alumina nanoparticles were shown in fig. 7. TGA analysis has shown no effect on thermal degradation properties of ABS polymer due to the addition of alumina nanoparticles.

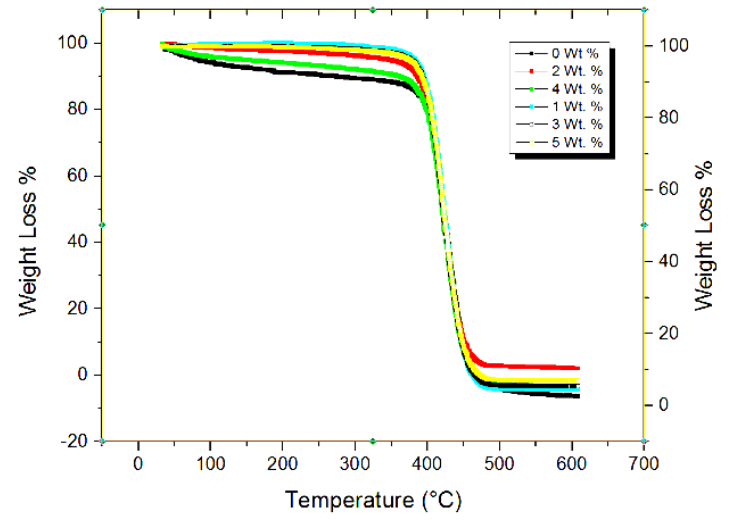

Figure 7: TGA curve for pure and alumina nanoparticles filled polymer.

\section{Mechanical tests of nanocomposites}

The trend of variation of elastic modulus and tensile strength of polymer nanocomposite with varying concentration of as received and surface treated alumina nanoparticles is presented in Figure 8and 9respectively. 
International Journal of Science and Research (IJSR)

ISSN (Online): 2319-7064

Index Copernicus Value (2013): 6.14 | Impact Factor (2014): 5.611

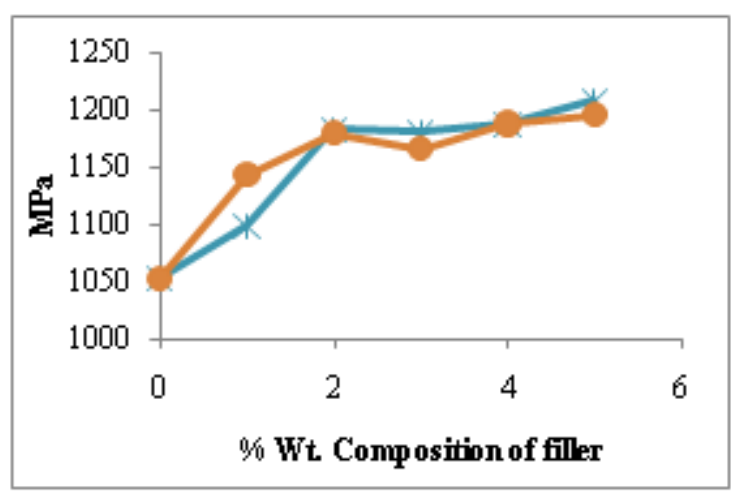

Figure 8: Plot of Young's modulus against nanofiller loading.

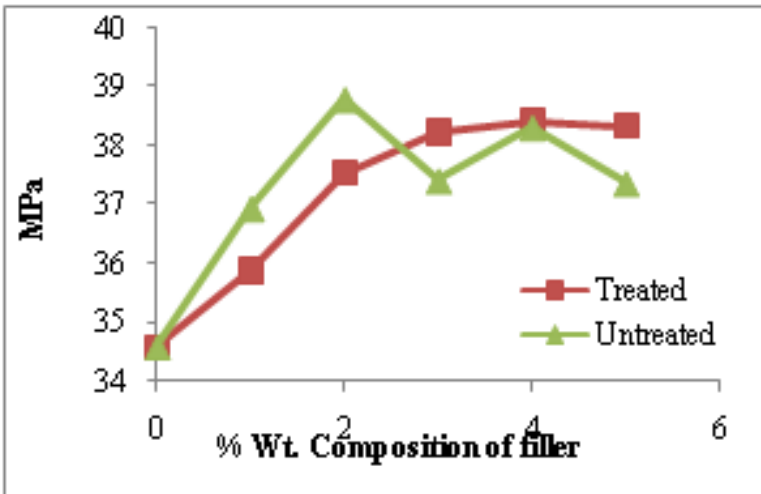

Figure 9: Tensile strength as a function of nanoparticle loading.

It was observed that as the concentration of as received alumina nanoparticles increases, tensile strength of the nanocomposite increases up to 2 wt. \% of nanofiller loading. With the further addition of nanofiller, tensile strength of the nanocomposite shows decreased in value. It was also observed that the tensile strength of nanocomposite with surface treated alumina nanocomposite increased to high value and maintains maxima even at higher nanoparticles loading. This is in accordance with the crystalinity data obtained from the XRD data. The MPS serves as a chemical bond linker between the particle surface and the resin matrix. This linkage facilitates the nanocomposite behaving like a unit, in which the tough nanoparticles make the resin stronger through chemical bonding, consistent with the fact that a good interfacial interaction has a strong effect on the mechanical properties. In addition, the chemical bonding between the nanoparticles and the polymeric matrix excludes air gaps, i.e. artificial defects between nanoparticles and the matrix, which would happen in the asreceived nanoparticle filled nanocomposite seen in Figure 9 and decrease the mechanical properties and the thermal stability.

The trend of variation of Young's modulus of polymer nanocomposite with varying concentration of alumina nanocomposite is presented in Figure 8. It was observed that the Young's modulus increase with the increased addition of both as received and surface treated alumina nanoparticles.

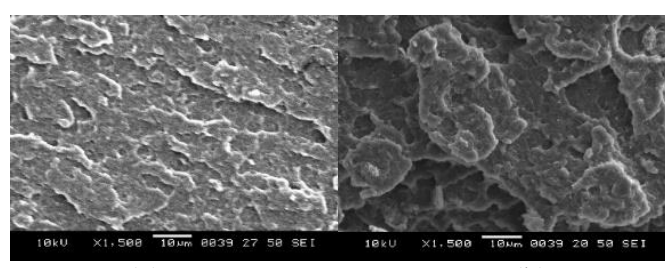

(a)

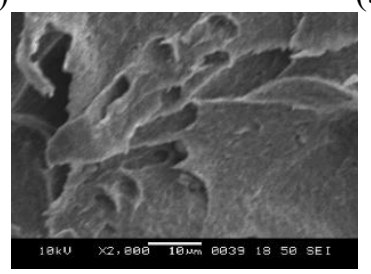

(b)

(c)

Figure 10: SEM micrographs of (a) the cured pure resin and

(b) the nanocomposite with 3 vol\% functionalized nanoparticle filling (inset in (b) shows the enlarged fracture surface with nanoparticles).

Figure10 (a), (b) and (c) are SEM micrographs of fracture surfaces for the neat resin and $3 \mathrm{wt}$ \% nanocomposite with as received and surface treated alumina nanoparticles. Even at the micron scale, the neat polymer shows a smooth fracture surface while the nanocomposite shows a rough fracture surface. This micro-rough structure can be attributed to the matrix shear yielding or local polymer deformation between the nanoparticles rather than the intra-particle propagating cracks due to the difficulty in breaking the alumina nanoparticle arising from the high hardness as compared with the resin matrix. The enlarged SEM image (the inset of Fig. 10(b)) showing the protruding nanoparticles also indicates that the cracks pass around the nanoparticle without damaging it, which was also observed in $\mathrm{Al}_{2} \mathrm{O}_{3} / \mathrm{CaSiO}_{3}$ filled epoxy nanocomposites [31]. The protruding nanoparticles seen on the nanocomposite surface are observed to be covered with the matrix polymer, indicating the presence of good adhesion between the nanoparticle and the polymer matrix through the chemical bonding [32]. In general, the presence of micron-size hard particles introduces stress concentrations, rendering the resulting composite more brittle than the matrix polymer itself. When nanosized particles are used, however, the enhanced mechanical properties (tensile strength and Young's modulus) were observed in the case of the functionalized nanoparticle distributed uniformly within the polymer matrix. This can be explained based on the stress within the polymeric matrix, the local stress can be more easily transferred into the tougher particle with the result that the matrix appears to be amenable to a larger local plastic deformation and the end result is a higher composite strength when the particles are in intimate contact with the polymer matrix. However, the voids between the nanoparticle and the polymer matrix and the nanoparticle agglomeration result in the decrease of the tensile strength.

\section{Wear Analysis}

Wear result obtained from wear analysis using weight loss method reveals decrease in wear rate by around $37.6 \%$ in case of surface treated nanoparticles and by $28.9 \%$ in case of untreated nanoparticles. Figure 11 shows decrease in wear rate with increase filler particle loading. 


\section{International Journal of Science and Research (IJSR) \\ ISSN (Online): 2319-7064}

Index Copernicus Value (2013): 6.14 | Impact Factor (2014): 5.611

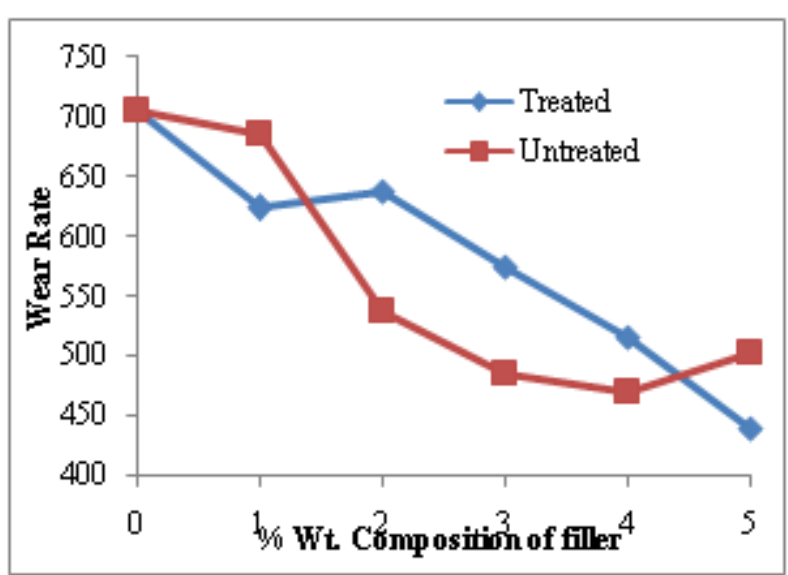

Figure 11: Wear rate as a function of filler particle loading.

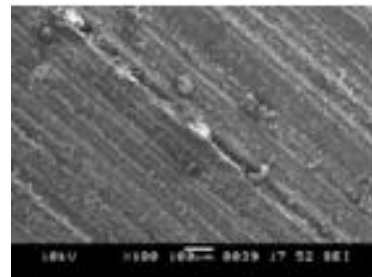

(a)

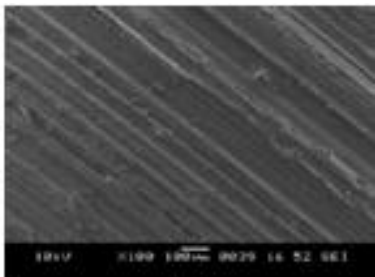

(b)
Figure 12: SEM micrographs of (a) the nanocomposite with

$5 \mathrm{vol} \%$ as received nanoparticle filling and (b) the nanocomposite with $5 \mathrm{vol} \%$ functionalized nanoparticle filling

Figure12 (a) and (b) are SEM micrographs of the wear tracks obtained for as received and surface treated alumina nanoparticles filled polymer nanocomposite. This is justified by the reports that the physicochemical interaction between the particle and the matrix plays a significant role in the obtained composites. In other words, the strong chemical bonding improves the mechanical properties of the composites as compared with the weak linkage by van der Waals and hydrogen bonding.

\section{Conclusion}

Alumina nanoparticles have been successfully functionalized with a bi-functional MPS coupling agents using neutral solvent method. With the addition of asreceived nanoparticles, the ABS polymer nanocomposites show decreased strength due to particle agglomeration and gas voids. After nanoparticle functionalization, the formed particle/matrix interfacial bonding allows for a larger local plastic deformation in the matrix. The net result is a significant increase in both modulus and strength. The addition of the functionalized nanoparticles has no deleterious effect on the thermal stability of the composite. The addition of the functionalized nanoparticles has shown improved wear resistance of the composite due to better chemical bounding between the nanofiller and polymer matrix.

\section{References}

[1] H. Nathani, A. Dasari and R. D. K.Misra: On the reduced susceptibility to stress whitening behavior of melt intercalated polybutene-clay nanocomposites during tensile straining Acta Mater., 2004, 52,32173227.

[2] R. D. K. Misra, H. Nathani and A. Dasari: The determining role of clay particles on mechanically induced surface damage and associated stress whitening in polybutene-clay Nanocomposites Mater. Sci. Eng. A,2004, 386A, 175-185.

[3] R. Hadal, Q. Yuan, J. P. Jog and R. D. K.Misra: On stress whitening during surface deformation in claycontaining polymer nanocomposites: A microstructural approachMater. Sci. Eng.A, 2006, A418, 268-281.

[4] F. P. La Mantia, S. L. Verso and N. T. Dintcheva: VA Copolymer Based Nanocomposites Macromol.Mater. Eng., 2002, 287, 909-914.

[5] P. B. Messersmith and E. P. Giannelis: Synthesis and Characterization of Layered Silicate-Epoxy Nanocomposites Chem. Mater., 1994, 6,1719-1725.

[6] R. J. Nussbaumer, W. R. Caseri, P. Smith and T. Tervoort:Polymer-TiO2 Nanocomposites: A Route Towards Visually Transparent Broadband UV Filters and High Refractive Index Material Macromol. Mater. Eng., 2003, 288, 44-49.

[7] Kornmann X., Lindberg H., Berglund L. A.: Synthesis of epoxy-clay nanocompsites: Influence of the nature of the clay on the structure. Polymer, 42, 1303-1310 (2001).

[8] E. P. Giannelis: NIST Ann. Conf. on 'Fire research', Gaithersburg, MD, USA, November 1998, Paper 6242 (p. 164).

[9] M. Z. Rong, M. Q. Zhang, Y. X. Zheng, H. M. Zeng, R. Walterand K. Friedrich: Structure-property relationships of irradiation grafted nano-inorganic particle filled polypropylene composites. Polymer, 2001, 42, 167183.

[10] C.B. Ng, B.J. Ash, L.S. Schadler, and R.W. Siegel, "A Study of the Mechanical and Permeability Properties of Nano- and Micron-TiO2 Filled Epoxy Composites," Advanced Composites Letters, 10, 101-111, (2001).

[11]C.B. Ng, L.S. Schadler, and R.W. Siegel, "Synthesis and Mechanical Properties of TiO2-Epoxy Nanocomposites," Nanostructured Materials, 12, 507510, (1999).

[12]R. W. Siegel, S. K. Chang, B. J. Ash, J. Stone, P. M. Ajayan, R. W. Doremus and L. S. Shadler: Scr. Mater., 2001, 44, 2065-2068.

[13] O. Okada and A. Usuki: Mater. Sci. Eng. C, 1995, 3C, 109-115.

[14]E. P. Giannelis, R. Krishnamoorti and E. Manias: Adv. Polym. Sci., 1999, 138, 107-147.

[15] J. W. Gilman, T. Kashiwaga, J. E. T. Brown, S. Lomankin, E. P. Giannelis and E. Manias: Proc. Int. SAMPE Symp., 1998, 43, 1053-1066.

[16] J. W. Gilman, C. L. Jackson, A. B. Morgan, R. Harris, E. Manias, E. P. Giannelis, M. Wuthenow and D. Hilton: Chem. Mater., 2000, 12, 1866-1873.

[17]ZhanhuGuo, Tony Pereira, Oyoung Choi, Ying Wang and H. Thomas Hahn: J. Mater. Chem., 2006, 16, 28002808.

[18]F. Mammeri, E. L. Bourhis, L. Rozes and C. Sanchez, J. Mater. Chem., 2005, 15, 3787.

[19]C. Sanchez and F. Ribot, New J. Chem., 1994, 18, 1007.

[20]P. Judeinstein and C. Sanchez, J. Mater. Chem., 1996, 6,511 .

\section{Volume 5 Issue 2, February 2016}




\section{International Journal of Science and Research (IJSR) \\ ISSN (Online): 2319-7064}

Index Copernicus Value (2013): 6.14 | Impact Factor (2014): 5.611

[21] R. Shenhar, T. B. Norsten and V. M. Rotello, Adv. Mater., 2005, 17, 657.

[22] D. J. Kim, P. H. Kang and Y. C. Nho, J. Appl. Polym. Sci., 2004,91, 1898.

[23] B. J. Ash, R. W. Siegel and L. S. Schadler, J. Polym. Sci., 2004, B42, 4371.

[24]K. A. DeFriend, M. R. Wiesner and A. R. Barron, J. Membr. Sci., 2003, 224, 11.

[25]B. J. Ash, R. W. Siegel and L. S. Schadler, Macromolecules, 2004, 37, 1358

[26] M. Zhang and R. P. Singh, Mater. Lett., 2005, 58, 408.

[27]F. Bauer, H.-J. Glasel, U. Decker, H. Ernst, A. Freyer, E. Hartmann, V. Sauerland and R. Mehnert, Prog. Org. Coat., 2003, 47, 147.

[28]P. Philipse and A. Vrij, J. Colloid Interface Sci., 1989, 128, 121.

[29] M. Pourbaix, Atlas of Electrochemical Equilibria In AqueousSolutions, Cebelcor, Houston, TX, 1974.

[30] M. Abboud, M. Turner, E. Duguet and M. Fontanille, J. Mater. Chem., 1997, 7, 1527.

[31]B. Wetzel, F. Haupert and M. Q. Zhang, Compos. Sci. Technol., 2003, 63, 2055.

[32] X. Zhang and L. C. Simon, Macromol. Mater. Eng., 2005, 290, 573. 